\title{
An Inter-Ethnic Comparison Study of Ziprasidone Plasma Levels, Dosage and Clinical Response in Patients with Schizophrenia
}

\author{
Dongsheng Lv ${ }^{1,4} \bowtie$, Meirong Zhao ${ }^{1,2}$, Lixia Chen ${ }^{1}$, Dongsheng $Y^{1}{ }^{1}$, \\ Xiaobin Yun ${ }^{1}$, Qing Yang ${ }^{3}$, and Xiaojun Huang ${ }^{4}$ \\ ${ }^{1}$ Department of Psychiatry, Mental Health Center of Inner Mongolia, Inner Mongolia, Hohhot, China \\ ${ }^{2}$ Department of Psychiatry, the First Affiliated Hospital of Inner Mongolia Medical University, Inner Mongolia, Hohhot, China \\ ${ }^{3}$ Department of Psychiatry, Yale School of Medicine, New Haven, CT, USA \\ ${ }^{4}$ Department of Psychiatry, Second Xiangya Hospital of Central South University, Changsha, China
}

Objective The aim of this study was to investigate ziprasidone plasma concentration, daily dose and clinical efficacy and safety in Han Chinese and Mongolian patients with first-episode schizophrenia.

Methods A total of 123 inpatients affected by schizophrenia were recruited from the Mental Health Center of Inner Mongolia in China. Ziprasidone plasma concentration, clinical efficacy and side effects were systematically evaluated at baseline, and at 1, 2, 4, and 6 weeks. Metabolic measures such as changes in weight, body mass index (BMI), fasting blood glucose (FBG), triglycerides, and cholesterol, were also recorded.

Results 90 patients completed the study. Compared with Han patients, on average, Mongolian patients received a significantly higher ziprasidone dosage for adequate symptom control during the 6-week period and had a lower plasma concentration-to-dose ratio. The Mongolian patients also experienced greater increases in weight and BMI. No significant differences between the two ethnic groups were found in the rate of reduction in the Positive and Negative Syndrome Scale (PANSS) score, Treatment Emergent Symptom Scale (TESS) total score, FBG, triglycerides, cholesterol or Q-Tc interval.

Conclusion Compared to Han Chinese patients, Mongolian patients appeared to have increased ziprasidone clearance and require higher doses to achieve effective treatment for schizophrenia.

Psychiatry Investig 2017;14(3):360-367

Key Words Ziprasidone, Ethnic disparity, Plasma concentration, Clinical efficacy, Side effects, Daily dosage.

\section{INTRODUCTION}

Ethnicity, a critical proxy for a person's culture, diet, beliefs, health behaviors and societal attitudes, has been reported to be an important factor in psychopharmacology. ${ }^{1}$ Previous studies have illustrated ethnic differences in clinical presentation, drug use, clinical response, ${ }^{2,3}$ and metabolism., ${ }^{4,5}$ To date, ethnic differences have been found in dosage, clinical efficacy, side effect and plasma concentrations of antipsychotics, ${ }^{6,7}$ antidepressants, ${ }^{8,9}$ lithium ${ }^{10,11}$ and benzodiazepines. ${ }^{12,13}$ Although

Received: October 31, 2015 Revised: April 14, 2016

Accepted: May 25, 2016 Available online: January 10, 2017

$\triangle$ Correspondence: Dongsheng Lv, MD, PhD

Department of Psychiatry, Mental Health Institute of Inner Mongolia, Wulanchabu Street, Xincheng District, Hohhot, Inner Mongolia 010010, China

Tel: +86-13848810596, Fax: +86-0471-6696641

E-mail: dongshenglv@163.com

(c) This is an Open Access article distributed under the terms of the Creative Commons Attribution Non-Commercial License (http://creativecommons.org/licenses/by$\mathrm{nc} / 4.0$ ) which permits unrestricted non-commercial use, distribution, and reproduction in any medium, provided the original work is properly cited. the observed ethnic differences could be partially explained by genetic factor, other variables such as culture, diet and societal attitudes may have significant influences as well. ${ }^{14,15}$

Studies suggest that Asian patients typically require lower dosages of antipsychotics than American or European patients. ${ }^{6,716,17}$ For instance, one study showed that Asian patients required a significantly lower mean clozapine dose (176 $\mathrm{mg} /$ day) than Caucasian patients $(433 \mathrm{mg} /$ day) to achieve similar plasma clozapine levels, resulting in more than twice the effective clozapine concentration to dose ratio. ${ }^{5}$ On the other hand, Asian patients were more sensitive to the side effects of antipsychotics, which may limit the dosage. ${ }^{6,718}$ Most of these studies are done in the US and Europe and little is known about how different ethnic groups within the Asian population compare. In addition, many Asian countries, including China, are ethnically heterogeneous and differences in pharmacological responses should be considered when treating patients to reduce the risk of possible idiosyncratic side effects 
or inappropriate dosing. ${ }^{19}$ The Inner Mongolia Autonomous Region (IMAR) of China is a geographical area in Northwest China adjacent to Mongolia. Its population of 25.05 million is composed of 79\% Han Chinese and 17\% Mongolian minority according to the 2010 National Census. Thus it is well suited to the study of ethnic differences in clinical responses. The atypical antipsychotic ziprasidone has been used for the treatment of schizophrenia in IMAR for more than 10 years. The medication has been commonly prescribed to both Han Chinese and Mongolian patients. It is thought to be effective and welltolerated in treating the positive, negative and depressive symptoms of an acute exacerbation of schizophrenia. ${ }^{20,21}$ However it is unclear whether ethnic differences exist in the metabolism, dosage requirement, efficacy, and safety of ziprasidone.

Ziprasidone is well absorbed after oral administration in the presence of food, reaching peak plasma concentrations in 6-8 h. It is mainly metabolized in the liver by aldehyde oxidase and microsomal enzyme cytochrome P450 (CYP) 3A4, forming ziprasidone sulfone and sulfoxide, which have little pharmacological effect compared to the parent drug. 22,23

One recent paper studied the efficacy and tolerability of fixed dose ziprasidone in placebo-controlled trials and concluded that the efficacy and safety profiles were similar in African-American and white schizophrenic patients. ${ }^{24}$ To the best of our knowledge, no published data are available for comparing the plasma concentrations and metabolic effects across different ethnicities (either major, such as Asian vs. Caucasian, or minor, such as Han vs. Mongolian). This study aimed to investigate the differences in ziprasidone plasma concentration, daily dosage, clinical response and safety between Han Chinese and Mongolian patients in IMAR with first-episode schizophrenia.

\section{METHODS}

\section{Participants}

A total of 123 patients aged 18-45 affected by first-episode schizophrenia were recruited from the mental health center of Inner Mongolia between July 2011 and December 2014. The inclusion criteria were: 1) meet the diagnostic criteria of schizophrenia according to DSM-IV, 2) in the exacerbation phase of an acute episode, and 3) Han Chinese or Mongolian ethnicity. We did not apply restrictions regarding smoking status because a previous study showed that smoking was unlikely to significantly affect ziprasidone pharmacokinetics. ${ }^{25}$ All patients were drug naïve, having never received any typical or atypical antipsychotics prior to the study. Exclusion criteria were: 1) agitation requiring haloperidol injection or electroconvulsive therapy, 2) medical comorbidities affecting the liver, kidney, digestive, hematologic or central nervous sys- tems, or any other concurrent serious physical illnesses, 3) abnormal laboratory values such as liver or kidney function tests, and 4) pregnant women or nursing mothers. The protocol was approved by the institutional ethics committee and written informed consent was obtained from the patients or their relatives prior to enrollment.

\section{Treatment regimen}

Ziprasidone tablets were started at $20 \mathrm{mg}$ taken twice daily with meals and increased to at least $80 \mathrm{mg}$ per day in the first week. In the following 5 weeks, the dose ranged from 80 to $160 \mathrm{mg}$ per day, as adjusted by the clinician based on individual responses and tolerability. The dose was kept constant for 3 days after each adjustment, there was no strict restriction on the number of dose adjustments within the 6-week period. ${ }^{22}$ Ziprasidone plasma concentrations, clinical responses, and daily dose were recorded. Other psychotropic medication and Chinese traditional herbal medication were prohibited for the duration of the study. Concomitant lorazepam (insomnia or agitation), benzhexol (extrapyramidal symptoms), and metoprolol (akathisia) were allowed if required during the study, but these agents were not prophylactically administered.

\section{Clinical assessment}

Patients were evaluated upon enrollment and at baseline, week 1 (T1), week 2 (T2), week 4 (T4) and week 6 (T6) by two raters. The Positive and Negative Syndrome Scale (PANSS ${ }^{26}$ was used to assess the degree of psychopathology. Side effect profiles were assessed using the Treatment Emergent Symptom Scale (TESS). ${ }^{27}$ Both raters were trained in use of the rating scales and performed the assessments independently, with a follow up session by a third rater to ensure inter-rater reliability. Data was collected on demographic information, smoking status, height, and weight. Changes from baseline to the end of the study in body mass index (BMI), electrocardiogram (ECG) Q-Tc interval, fasting blood glucose (FBG), triglycerides and cholesterol were also recorded.

\section{Assay of plasma ziprasidone concentration}

The ziprasidone plasma concentrations were measured at T1, T2, T4 and T6 after patients were maintained on a steady dose for at least 3 days for each time point. Briefly, heparinized blood samples $(10 \mathrm{~mL})$ were collected in the early morning (between 06:30 and 08:00 am), 1.1 $\pm 0.5 \mathrm{~h}$ before the morning dose and $11 \pm 1.5 \mathrm{~h}$ after the last dose. ${ }^{22}$ Samples were centrifuged at $3000 \mathrm{rpm}$ for $5 \mathrm{~min}$ and plasma was stored at $-20^{\circ} \mathrm{C}$ until analysis, which was performed within five days. Drug concentration in plasma was determined by high-performance liquid chromatography (HPLC) via ultraviolet detection 
at $229 \mathrm{~nm}$, with diazepam as the internal standard. The compounds were separated on a SHIMADZU $\mathrm{C}_{18}$ column $(5 \mu \mathrm{m}$, $150 \times 4.6 \mathrm{~mm})$. The mobile phase was a mixture of methanol- water-four ethylenediamine-glacial acetic acid (70:30: 2.0:1.6 $\mathrm{vol} / \mathrm{vol} / \mathrm{vol} / \mathrm{vol}$ ), the flow rate was $1.15 \mathrm{~mL} / \mathrm{min}$. The column temperature was $40^{\circ} \mathrm{C}$. The lowest detection concentration

Table 1. Clinical characteristics of Han and Mongolian patients

\begin{tabular}{|c|c|c|c|c|}
\hline \multirow{2}{*}{ Items } & \multirow{2}{*}{ Han Chinese } & \multirow{2}{*}{ Mongolian } & \multicolumn{2}{|c|}{ Significance } \\
\hline & & & $t / \chi^{2}$ & p 2-tail \\
\hline Sample size & 48 & 42 & - & - \\
\hline Age (years) $(\mathrm{M} \pm \mathrm{SD})$ & $29.75(7.82)$ & $29.64(8.12)$ & 0.064 & 0.949 \\
\hline Genders (M/F) & $26 / 22$ & $22 / 20$ & 0.029 & 0.865 \\
\hline Weight $(\mathrm{kg})$ baseline & $65.07(7.61)$ & $73.94(7.10)$ & -5.691 & $1.62 \times 10^{-7}$ \\
\hline BMI $\left(\mathrm{kg} / \mathrm{m}^{2}\right)$ baseline & $24.69(2.29)$ & $26.32(2.10)$ & -3.500 & 0.001 \\
\hline Weight MC (kg) $(\mathrm{M} \pm \mathrm{SD})$ & $-0.24(0.93)$ & $0.25(0.82)$ & -2.624 & 0.010 \\
\hline $\mathrm{BMI}\left(\mathrm{kg} / \mathrm{m}^{2}\right) \mathrm{MC}(\mathrm{M} \pm \mathrm{SD})$ & $-0.09(0.35)$ & $0.08(0.30)$ & -2.499 & 0.014 \\
\hline Smoker/non-smoker & $25 / 23$ & $22 / 20$ & 0.000 & 0.978 \\
\hline \multicolumn{5}{|l|}{ PANSS Scores (baseline) $(\mathrm{M} \pm \mathrm{SD})$} \\
\hline PANSS total score & $81.21(10.46)$ & $79.50(10.09)$ & 0.785 & 0.434 \\
\hline Positive Symptom score & $27.06(7.12)$ & $26.57(6.77)$ & 0.334 & 0.739 \\
\hline Negative Symptom score & $26.73(7.09)$ & $23.98(65.72)$ & 2.035 & 0.045 \\
\hline General Psychopathology score & $27.42(4.49)$ & $28.95(5.84)$ & -1.407 & 0.163 \\
\hline \multicolumn{5}{|l|}{ PANSS Scores (1 week) $(\mathrm{M} \pm \mathrm{SD})$} \\
\hline PANSS total score & $75.81(8.97)$ & $74.86(9.71)$ & 0.485 & 0.629 \\
\hline Positive Symptom score & $26.00(6.84)$ & $25.74(6.68)$ & 0.183 & 0.855 \\
\hline Negative Symptom score & $24.50(6.32)$ & $22.07(4.94)$ & 2.043 & 0.044 \\
\hline General Psychopathology score & $25.19(4.09)$ & $26.79(5.76)$ & -1.498 & 0.138 \\
\hline \multicolumn{5}{|l|}{ PANSS Scores ( 2 weeks) $(\mathrm{M} \pm \mathrm{SD})$} \\
\hline PANSS total score & $71.50(7.94)$ & $70.40(8.47)$ & 0.633 & 0.528 \\
\hline Positive Symptom score & $24.85(6.18)$ & $24.90(6.20)$ & -0.039 & 0.969 \\
\hline Negative Symptom score & $22.88(5.88)$ & $20.57(4.20)$ & 2.158 & 0.034 \\
\hline General Psychopathology score & $23.69(3.87)$ & $24.93(4.88)$ & -1.324 & 0.189 \\
\hline \multicolumn{5}{|l|}{ PANSS Scores (4 weeks) $(\mathrm{M} \pm \mathrm{SD})$} \\
\hline PANSS total score & $64.60(6.54)$ & $62.38(9.52)$ & 1.305 & 0.195 \\
\hline Positive Symptom score & $22.67(5.04)$ & $21.81(5.47)$ & 0.774 & 0.441 \\
\hline Negative Symptom score & $20.73(4.61)$ & $18.62(3.56)$ & 2.405 & 0.018 \\
\hline General Psychopathology score & $21.04(3.06)$ & $21.95(4.87)$ & -1.044 & 0.300 \\
\hline \multicolumn{5}{|l|}{ PANSS Score ( 6 weeks) $(\mathrm{M} \pm \mathrm{SD})$} \\
\hline PANSS total score & $59.31(7.42)$ & $57.93(9.63)$ & 0.755 & 0.452 \\
\hline Positive Symptom score & $20.96(4.60)$ & $20.90(5.06)$ & 0.053 & 0.958 \\
\hline Negative Symptom score & $18.52(4.27)$ & $16.07(3.23)$ & 3.088 & 0.003 \\
\hline General Psychopathology score & $19.56(3.52)$ & $20.90(4.88)$ & -1.508 & 0.135 \\
\hline \multicolumn{5}{|c|}{ ECG and laboratory examination $(\mathrm{M} \pm \mathrm{SD})$} \\
\hline Q-Tc interval MC (ms) & $9.29(10.53)$ & $8.33(9.35)$ & 0.454 & 0.651 \\
\hline Glucose $\mathrm{MC}(\mathrm{mmol} / \mathrm{L})$ & $0.11(0.36)$ & $0.12(0.30)$ & -0.205 & 0.838 \\
\hline Triglycerides MC( mmol/L) & $0.19(0.22)$ & $0.15(0.21)$ & 0.832 & 0.408 \\
\hline Cholesterol MC( mmol/L) & $0.24(0.37)$ & $0.32(0.24)$ & -1.315 & 0.192 \\
\hline
\end{tabular}

M: mean, SD: standard deviation, BMI: Body Mass Index, PANSS: Positive and Negative Syndrome Scale, ECG: electrocardiogram, MC: mean change from baseline to end of study 
Table 2. Comparison of ziprasidone plasma concentration, dosage and clinical response between two groups at the T1, T2, T4 and T6

\begin{tabular}{|c|c|c|c|c|c|c|c|c|c|c|c|c|}
\hline \multirow{2}{*}{ Items } & \multicolumn{4}{|c|}{ Han Chinese } & \multicolumn{4}{|c|}{ Mongolian } & \multicolumn{4}{|c|}{ Han vs Mongolian (p) } \\
\hline & $\mathrm{T} 1$ & $\mathrm{~T} 2$ & $\mathrm{~T} 4$ & T6 & $\mathrm{T} 1$ & $\mathrm{~T} 2$ & $\mathrm{~T} 4$ & T6 & $\mathrm{p} 1$ & $\mathrm{p} 2$ & $\mathrm{p} 4$ & p6 \\
\hline $\begin{array}{l}\text { Zip CP }(\mathrm{M} \pm \mathrm{SD}) \\
(\mathrm{ng} / \mathrm{mL})\end{array}$ & $\begin{array}{c}65.81 \\
(15.04)\end{array}$ & $\begin{array}{c}82.45 \\
(14.33)\end{array}$ & $\begin{array}{c}99.47 \\
(22.77)\end{array}$ & $\begin{array}{l}104.60 \\
(24.11)\end{array}$ & $\begin{array}{c}61.83 \\
(12.18)\end{array}$ & $\begin{array}{c}78.39 \\
(14.65)\end{array}$ & $\begin{array}{c}91.84 \\
(16.31)\end{array}$ & $\begin{array}{c}96.29 \\
(17.29)\end{array}$ & 0.174 & 0.187 & 0.075 & 0.067 \\
\hline $\begin{array}{l}\text { Zip CPs/Dose }( \pm \text { SD }) \\
(\mathrm{ng} / \mathrm{mL}) / \mathrm{mg}\end{array}$ & $\begin{array}{c}0.80 \\
(0.21)\end{array}$ & $\begin{array}{c}0.73 \\
(0.17)\end{array}$ & $\begin{array}{c}0.80 \\
(0.18)\end{array}$ & $\begin{array}{c}0.76 \\
(0.16)\end{array}$ & $\begin{array}{c}0.71 \\
(0.17)\end{array}$ & $\begin{array}{c}0.64 \\
(0.13)\end{array}$ & $\begin{array}{c}0.63 \\
(0.12)\end{array}$ & $\begin{array}{c}0.64 \\
(0.12)\end{array}$ & 0.046 & 0.004 & $2.13 \times 10^{-6}$ & $6.70 \times 10^{-5}$ \\
\hline $\begin{array}{l}\text { Dose }(\mathrm{M} \pm \mathrm{SD}) \\
(\mathrm{mg} / \mathrm{d})\end{array}$ & $\begin{array}{c}84.17 \\
(10.88)\end{array}$ & $\begin{array}{l}114.17 \\
(14.27)\end{array}$ & $\begin{array}{l}126.25 \\
(14.96)\end{array}$ & $\begin{array}{l}138.75 \\
(18.18)\end{array}$ & $\begin{array}{c}88.10 \\
(11.74)\end{array}$ & $\begin{array}{r}123.33 \\
(8.74)\end{array}$ & $\begin{array}{l}147.14 \\
(11.54)\end{array}$ & $\begin{array}{l}152.38 \\
(11.65)\end{array}$ & 0.103 & 0.001 & $1.02 \times 10^{-9}$ & $7.18 \times 10^{-5}$ \\
\hline $\begin{array}{l}\text { Dose/Weight }(\mathrm{M} \pm \mathrm{SD}) \\
(\mathrm{mg} / \mathrm{kg})\end{array}$ & $\begin{array}{c}1.38 \\
(0.25)\end{array}$ & $\begin{array}{c}1.88 \\
(0.37)\end{array}$ & $\begin{array}{c}2.07 \\
(0.41)\end{array}$ & $\begin{array}{c}2.26 \\
(0.39)\end{array}$ & $\begin{array}{c}1.24 \\
(0.23)\end{array}$ & $\begin{array}{c}1.73 \\
(0.23)\end{array}$ & $\begin{array}{c}2.05 \\
(0.25)\end{array}$ & $\begin{array}{c}2.13 \\
(0.29)\end{array}$ & 0.006 & 0.029 & 0.867 & 0.081 \\
\hline Responder/non & $5 / 43$ & $20 / 28$ & $36 / 12$ & $40 / 8$ & $5 / 37$ & $16 / 26$ & $30 / 12$ & $32 / 10$ & 0.823 & 0.730 & 0.702 & 0.389 \\
\hline \multicolumn{13}{|l|}{ PANSS RR (\%) } \\
\hline $\begin{array}{l}\text { PANSS Total Score } \\
(\mathrm{M} \pm \mathrm{SD})\end{array}$ & $\begin{array}{l}10.21 \\
(5.20)\end{array}$ & $\begin{array}{l}18.34 \\
(7.20)\end{array}$ & $\begin{array}{c}30.81 \\
(13.45)\end{array}$ & $\begin{array}{c}40.39 \\
(18.18)\end{array}$ & $\begin{array}{c}9.35 \\
(5.82)\end{array}$ & $\begin{array}{l}17.97 \\
(8.34)\end{array}$ & $\begin{array}{c}33.54 \\
(18.10)\end{array}$ & $\begin{array}{c}42.17 \\
(20.35)\end{array}$ & 0.464 & 0.821 & 0.425 & 0.663 \\
\hline $\begin{array}{l}\text { Positive Symptom Score } \\
(\mathrm{M} \pm \mathrm{SD})\end{array}$ & $\begin{array}{c}5.44 \\
(4.01)\end{array}$ & $\begin{array}{l}10.76 \\
(6.00)\end{array}$ & $\begin{array}{c}20.17 \\
(11.27)\end{array}$ & $\begin{array}{c}27.67 \\
(16.46)\end{array}$ & $\begin{array}{c}4.70 \\
(5.07)\end{array}$ & $\begin{array}{c}8.36 \\
(5.73)\end{array}$ & $\begin{array}{c}23.46 \\
(14.76)\end{array}$ & $\begin{array}{c}27.75 \\
(15.41)\end{array}$ & 0.446 & 0.057 & 0.243 & 0.981 \\
\hline $\begin{array}{l}\text { Negative Symptom Score } \\
(\mathrm{M} \pm \mathrm{SD})\end{array}$ & $\begin{array}{c}11.36 \\
(06.20)\end{array}$ & $\begin{array}{l}19.56 \\
(8.93)\end{array}$ & $\begin{array}{c}29.10 \\
(14.20)\end{array}$ & $\begin{array}{c}39.52 \\
(18.26)\end{array}$ & $\begin{array}{l}10.73 \\
(6.92)\end{array}$ & $\begin{array}{l}18.72 \\
(9.20)\end{array}$ & $\begin{array}{c}28.60 \\
(18.02)\end{array}$ & $\begin{array}{c}42.86 \\
(22.09)\end{array}$ & 0.649 & 0.659 & 0.894 & 0.435 \\
\hline $\begin{array}{l}\text { General Psychopathology } \\
\text { Score }(\mathrm{M} \pm \mathrm{SD})\end{array}$ & $\begin{array}{l}10.60 \\
(7.73)\end{array}$ & $\begin{array}{c}17.55 \\
(10.58)\end{array}$ & $\begin{array}{c}29.29 \\
(15.58)\end{array}$ & $\begin{array}{c}36.02 \\
(19.93)\end{array}$ & $\begin{array}{c}9.96 \\
(7.94)\end{array}$ & $\begin{array}{c}17.58 \\
(11.07)\end{array}$ & $\begin{array}{c}30.17 \\
(20.34)\end{array}$ & $\begin{array}{c}34.34 \\
(22.65)\end{array}$ & 0.698 & 0.990 & 0.818 & 0.709 \\
\hline $\mathrm{TESS}(\mathrm{M} \pm \mathrm{SD})$ & $\begin{array}{c}7.17 \\
(2.82)\end{array}$ & $\begin{array}{l}13.48 \\
(3.29)\end{array}$ & $\begin{array}{l}12.79 \\
(3.67)\end{array}$ & $\begin{array}{c}9.52 \\
(3.50)\end{array}$ & $\begin{array}{c}6.71 \\
(2.28)\end{array}$ & $\begin{array}{l}12.36 \\
(3.16)\end{array}$ & $\begin{array}{l}12.24 \\
(2.58)\end{array}$ & $\begin{array}{c}8.69 \\
(2.70)\end{array}$ & 0.409 & 0.104 & 0.417 & 0.195 \\
\hline
\end{tabular}

T1, T2, T4 and T6, week 1, week 2, week 4 and week 6 after ziprasidone treatment. Zip CPs: ziprasidone plasma concentration, Zip CPs/Dose: ziprasidone plasma concentration per mg dosage, Dose/Weight: ziprasidone daily dosage per kg weight, responder/non responder/non-responder, PANSS RR: Reducing Rates of Positive and Negative Syndrome Scale and Subscales, TESS: Treatment Emergent Symptom Scale

assayed was $18 \mathrm{ng} / \mathrm{mL}$. The average recovery ratio was $99.9 \%$. The within and inter-day coefficients of variations were $<5 \%$, and the standard curves were linear within the range of $40^{-}$ $640 \mathrm{ng} / \mathrm{mL}$.

\section{Data management and statistical analysis}

Patients were classified as 'responders' or 'non-responders' on the basis of reducing rates (RR) of PANSS score $\geq 20 \%$. RR of PANSS=(baseline score-score at the T1st, T2ed, T4th or T6th) $/($ baseline score -30$) \times 100 \%$; RR of PANSS subscales $=$ (baseline score-score at the T1st, T2ed, T4th or T6th)/(baseline score -7$) \times 100 \%$.

All data was managed and analyzed using Windows SPSS 19.0 (IBM). All measurements were evaluated with normality plots and the Levene test for homogeneity of variances. Inter-group comparisons were performed using t-tests or MannWhitney U tests for continuous variables (age, PANSS score, TESS score, daily dosage, ziprasidone plasma concentration, and mean changes in weight, BMI, Q-Tc, FBG, triglycerides, and cholesterol) and chi-square test for dichotomous variables and proportions (sex, smoking status, and remission rate). Time dependent changes in ziprasidone plasma concentration, daily dosage, and clinical response at T1, T2, T4 and T6 with- in each group were assessed with one-way ANOVA and post hoc multiple comparisons (LSD test for equal variance and Dunnett's T3 test for unequal variance). Daily dosage requirement and ziprasidone plasma concentration to dose ratios were calculated and compared between the two groups, using baseline weight and BMI as covariates. All statistical tests were twotailed, and $\mathrm{p}<0.05$ was considered statistically significant.

\section{RESULTS}

\section{Clinical characteristics}

A total of 123 patients at $18-45$ years of age (28.64 \pm 8.26$)$ were recruited; 33 patients (17 Han Chinese, 16 Mongolian) did not complete the study for the following reasons: patient refusal (15); switched to alternative medications or combination with other antipsychotics drugs (8); unable to obtain blood sample (6); non-compliance with treatment regimen (4). Ninety patients (48 Han Chinese, 42 Mongolian) completed the trial and were included in the final analysis. Characteristics of the two groups are summarized in Table 1. Compared to the Mongolian patients, Han Chinese patients had significantly lower BMI and weight $(\mathrm{p}<0.01)$ at baseline. No significant differences were found in age distribution, gender, and smoking status. 


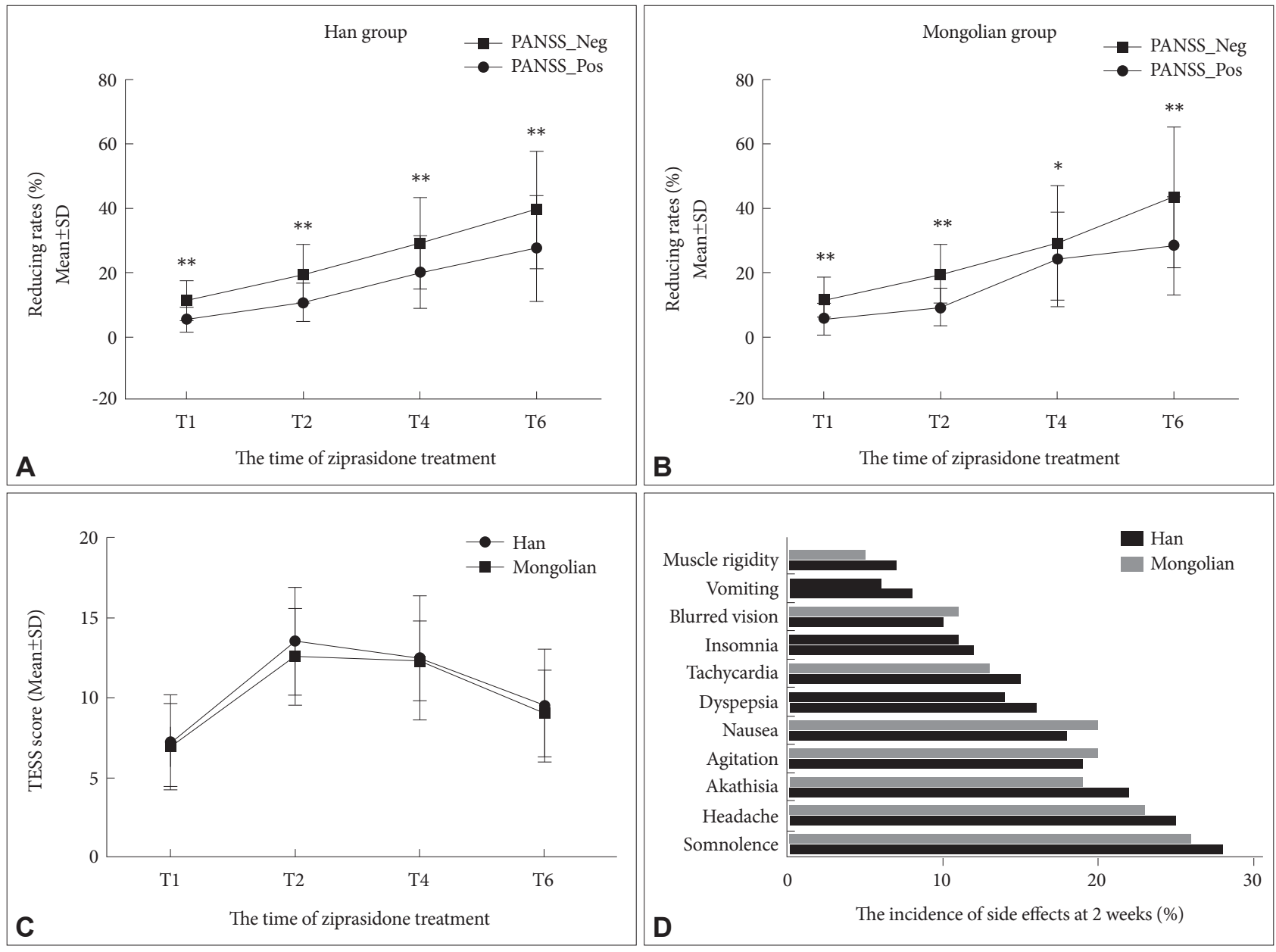

Figure 1. Clinical efficacy and side effects profiles for Han Chinese and Mongolian patients during the 6-week treatment with ziprasidone (A and $B$ ). Reduction rates in positive and negative symptom scores in Han (A) and Mongolian (B) patients. Negative symptom scores decrease at a faster rate than positive symptom scores in both groups $(p<0.05)$. C: Changes in the mean TESS scores. The mean TESS scores gradually increase during the study, plateauing at T2 to T4, then decline at T6, although the T6 score is still significantly higher than at T1 $(p<0.01)$. No significant difference in the peak TESS score is seen between the two ethnic groups ( $>0.05)$. D: Incidence of adverse reactions at 2 weeks after ziprasidone treatment. ${ }^{*} p<0.05,{ }^{* *} p<0.01$. TESS: Treatment Emergent Symptom Scale.

\section{Daily dosage and plasma concentration of ziprasidone}

No significant difference in ziprasidone plasma concentration was noted between the two groups throughout the treatment period $(\mathrm{p}>0.05)$. However, the dosage taken by the Mongolian patients was larger at $\mathrm{T} 2(123+/-8.74 \mathrm{mg})(\mathrm{p}=0.001), \mathrm{T} 4$ $(147+/-11.54 \mathrm{mg})(\mathrm{p}<0.001)$ and $\mathrm{T} 6(152.38+/-11.65 \mathrm{mg})$ $(\mathrm{p}<0.001)$ (Table 2). Baseline weight had significant effect on daily mean dose difference at $\mathrm{T} 6$ only $(\mathrm{p}=0.014)$. Furthermore, in view of the weight difference between the two groups, the ziprasidone dosage was recalculated as dosage/weight ratios. The mean weight-corrected dosages for Han patients were significantly higher than Mongolian patients at $\mathrm{T} 1(\mathrm{p}=0.006)$ and T2 ( $\mathrm{p}=0.029)$, but not at T4 or T6 ( $>0.05)$ (Table 2). The plasma concentration to dose ratios were significantly higher for the Han Chinese group than the Mongolian group at all four time points T1, T2, T4 and T6 ( $<<0.05)$ (Table 2). Addi- tionally, BMI had no significant effect on the ziprasidone plasma concentration to dosage ratio. The differences in ziprasidone plasma concentration to dose ratios between the ethnic groups remained significant at $\mathrm{T} 2(\mathrm{p}=0.009), \mathrm{T} 4(\mathrm{p}<0.001)$ and T6 ( $\mathrm{p}=0.001)$ when BMI was accounted as a co-variable.

\section{Clinical efficacy and safety comparison between the two ethnic groups}

The mean clinical rating scores for the two ethnic groups are presented in Table 1. The Han Chinese patients exhibited significantly higher negative symptom scores than the Mongolian patients at both the baseline and the end of the trial $(\mathrm{p}<0.05)$. There was no significant intergroup difference in the Reducing Rates of PANSS total and subscales scores (Table 2). Nevertheless, we found that the rate of reduction in the negative symptom scores was faster than in the positive scores for both groups $(\mathrm{p}<0.01)$ (Figure 1A). After the 6-week treat- 


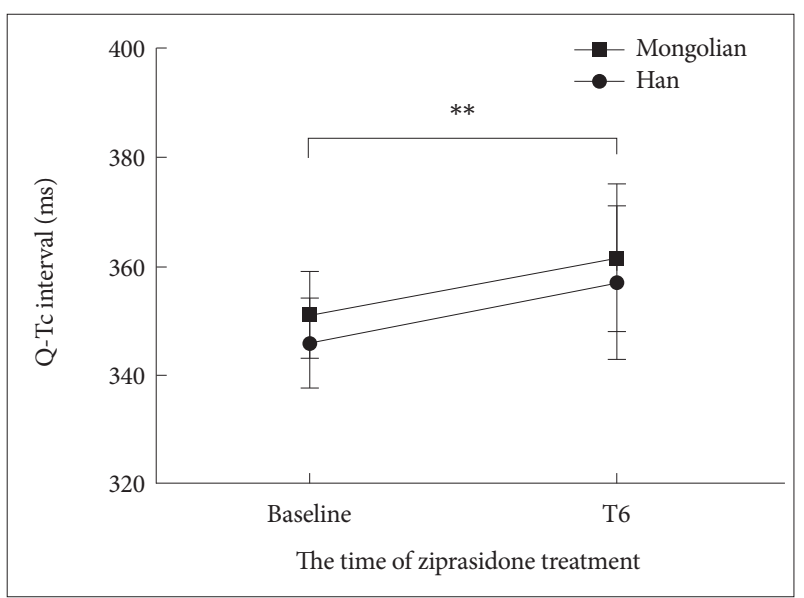

Figure 2. Q-Tc interval at baseline and the end of the study for Han and Mongolian patients. The Q-Tc interval significantly increased for both groups $(p<0.01)$. ${ }^{* *} p<0.01$.

ment, the Mongolian patients experienced significantly greater changes in weight and BMI than did the Han patients, but the changes in FBG, triglycerides and cholesterol from baseline to the end point were similar ( $\mathrm{p}>0.05)$ (Table 1). There was no difference in remission rates ( $40 / 48$ vs. $32 / 42$, $\mathrm{p}=0.389$ ) or TESS score changes from T1 to T6 ( $\mathrm{p}>0.05$ ) between the two groups (Table 2). Both groups experienced similar side effects, including somnolence, headache, akathisia, transient agitation, nausea and vomiting, and dyspepsia (Figure 1D). The Q-Tc interval was significantly prolonged from the baseline to the end of the study $(\mathrm{p}<0.01)$; the Han Chinese and Mongolian patients exhibited increases of approximately $9+/-10.35 \mathrm{~ms}$ and $8+/-9.35 \mathrm{~ms}$, respectively, but the change was similar for both groups (Figure 2). Additional comparison of the pharmacology and efficacy of Ziprasidone between the two ethnic groups is presented in the Supplementary Table 1, 2 in the online-only data supplement.

\section{DISCUSSION}

This study investigated the differences in the dosing requirement, plasma concentration, clinical efficacy, and safety of ziprasidone between Han Chinese and Mongolian patients over a 6-week treatment period. To the best of our knowledge, this is the first study to explore the ethnicity-dependence of atypical antipsychotics in two Asian populations. The key findings include: 1) In both ethnic groups, as the treatment period progressed, the plasma concentration of ziprasidone and mean daily dosages increased, accompanied by alleviation of symptoms as shown by the PANSS scale, 2) Dosage requirement to achieve therapeutic plasma concentration of ziprasidone was lower and the concentration to dose ratio was higher for Han Chinese than for Mongolian patients. 3) There were no differences in clinical efficacies and safety profiles between the two ethnic groups.

Our findings illustrate significant ethnic differences in the pharmacokinetics of ziprasidone. Han Chinese patients may have a slower metabolism for ziprasidone given their higher plasma concentration to daily dose ratio. In vitro data using human liver microsomes showed that approximately twothirds of ziprasidone metabolism occurs via aldehyde oxidasemediated reduction, and one-third via cytochromes $\mathrm{P} 450$ (CYP) 3A4 ${ }^{28,29}$ Aldehyde oxidase was not known to be subject to genetic polymorphism that results in functional consequences in ziprasidone metabolism. ${ }^{30}$ However, up to 40 -fold individual variability, leading to variations in drug metabolism and individual responses, was observed in the expression of CYP3A4. ${ }^{31}$ Although the association of the CYP3A4 genetic polymorphism with ziprasidone metabolism is unknown, we believe that genetic factors partly contribute to the metabolic differences between the two ethnic groups.

Non-genetic variables may also play a role. Previous study reported that different ethnic groups have great discrepancies in diet, belief and attitude toward psychiatric diseases. ${ }^{15}$ Diet has been found to alter the pharmacokinetic properties of medications. ${ }^{32,33}$ The dietary habits are remarkably different between Han and Mongolian populations-the Han diet, with its agricultural roots, contains vegetables and grains as the major food groups, whereas the nomadic Mongolian diet is rich in protein and fat. ${ }^{34-36}$ The food intake patterns may contribute to the differences observed in baseline weight and $\mathrm{BMI}$, which in turn affected the medication dosing. Since the two ethnic groups had different baseline weights at the beginning of the study, we considered this a confounding factor.

In addition, protein binding within the blood can result in individual variations in the concentration of the active drug. From an ethnic perspective, variations have been found in the absolute of concentration of al-acid glycoprotein and the distribution of its two variants. One of these variants varies in frequency from $15-27 \%$ in Asians to $34-67 \%$ in Caucasians and African-Americans..$^{37-39}$ Furthermore, Ziprasidone, like other atypical antipsychotics is a substrate of the efflux transporter P-glycoprotein (P-gp) in mice. ${ }^{40}$ Theoretically, this could have clinically relevant effects in patients with genetically determined differences in P-gp gene activity. However, it remains unknown whether any of the three major singlenucleotide polymorphism in the P-gp gene (ABCB1), which can be present in up to $93 \%$ of the populations of some ethnicities, have negative, positive or neutral effects on the overall activity of this protein. ${ }^{41}$

Some patients in both groups were taking concomitant medications during the study, which may confound the metabolism of ziprasidone. However, CYP3A4 in human liver microsomes had no significant interaction with co-administered CYP sub- 
strates across the clinical dosage range, ${ }^{42}$ and there are no reported clinical interactions with aldehyde oxidase inhibitors or inducers, ${ }^{30}$ making it unlikely that concomitant medications contributed to the pharmacokinetic discrepancies observed in our study. In addition, a multitude of studies have demonstrated that there are no significant change in the pharmacokinetics of ziprasidone based on age, gender, and smoking status. ${ }^{25,43}$ In our study, the patients from the two ethnic groups were matched for age, gender, and smoking status. Additionally, the ethnic difference in ziprasidone plasma concentration to dose ratio was preserved even after controlling for age, gender, smoking status, baseline weights and BMI were controlled in our analysis.

Our current study showed that ziprasidone has excellent efficacy and tolerability in the treatment of first-episode schizophrenics for both Han Chinese and Mongolians. This is consistent with previous studies that have demonstrated the clinical efficacy of the drug in Caucasians, African Americans and Asians..$^{20,24,44}$ Our study confirmed that ziprasidone treatment was associated with fewer adverse effects, including risks for metabolic syndrome, such as higher FBG and lipid levels. ${ }^{45}$ Finally, although the inter-group difference was nonsignificant, Q-Tc intervals did universally increase after treatment with ziprasidone. A previous study revealed this to be a non-linear dose-dependent phenomenon, ${ }^{46}$ but even high doses of ziprasidone did not result in Q-Tc interval $>450 \mathrm{~ms}^{47}$ Therefore we also advocate that ziprasidone may be safely used with ECG monitoring in clinical practice.

A limitation of this study was that a flexible dose according to clinical judgment rather than a fixed-dose was used during the course of treatment. This made it difficult for us to precisely monitor metabolism and clearance. In clinical practice, clinicians usually increase the dose of ziprasidone for patients who exhibit poor responses, resulting in non-responders receiving higher doses. This was a relatively short trial, lasting only 6 weeks. Future studies of longer duration using a fixeddose regimen would be helpful for further investigating the ethnic differences. Correlation with genetic studies would also be of interest.

In conclusion, ziprasidone exhibited good clinical efficacy and safety profiles in both Han Chinese and Mongolian ethnic groups. Based on our findings, we recommend that dose requirements should be taken into account when treating patients of different ethnicities.

\section{Supplementary Materials}

The online-only Data Supplement is available with this article at https://doi.org/10.4306/pi.2017.14.3.360.

\section{Acknowledgments}

The authors thank Chunmei Cheng and Shuying Bai for collecting clini- cal data; Ruiting Ma and Bo Gao for offering laboratory analysis. The Natural Science Foundation of Inner Mongolia Autonomous Region provided the funding (No: 2009MS1156). This study is dedicated to and in memory of my mentor, Prof Zhigang Wang.

\section{REFERENCES}

1. Pi EH. Transcultural psychopharmacology: present and future. Psychiatry Clin Neurosci 1998;52(Suppl):S185-S187.

2. Kuno E, Rothbard AB. Racial disparities in antipsychotic prescription patterns for patients with schizophrenia. Am J Psychiatry 2002;159:567-572.

3. Chan LF, Zai C, Monda M, Potkin S, Kennedy JL, Remington G, et al. Role of ethnicity in antipsychotic-induced weight gain and tardive dyskinesia: genes or environment? Pharmacogenomics 2013;14:12731281.

4. Bigos KL, Pollock BG, Coley KC, Miller DD, Marder SR, Aravagiri M, et al. Sex, race, and smoking impact olanzapine exposure. J Clin Pharmacol 2008;48:157-165.

5. Ng CH, Chong SA, Lambert T, Fan A, Hackett LP, Mahendran R, et al. An inter-ethnic comparison study of clozapine dosage, clinical response and plasma levels. Int Clin Psychopharmacol 2005;20:163-168.

6. Matsuda KT, Cho MC, Lin KM, Smith MW, Young AS, Adams JA. Clozapine dosage, serum levels, efficacy, and side-effect profiles: a comparison of Korean-American and Caucasian patients. Psychopharmacol Bull 1996;32:253-257.

7. Subramaniam M, Ng C, Chong SA, Mahendran R, Lambert T, Pek E, et al. Metabolic differences between Asian and Caucasian patients on clozapine treatment. Hum Psychopharmacol 2007;22:217-222.

8. Varner RV, Ruiz P, Small DR. Black and white patients response to antidepressant treatment for major depression. Psychiatr Q 1998;69:117125.

9. Lesser IM, Myers HF, Lin KM, Bingham Mira C, Joseph NT, Olmos NT, et al. Ethnic differences in antidepressant response: a prospective multi-site clinical trial. Depress Anxiety 2010;27:56-62.

10. Strickland TL, Lin KM, Fu P, Anderson D, Zheng Y. Comparison of lithium ratio between African-American and Caucasian bipolar patients. Biol Psychiatry 1995;37:325-330.

11. Gonzalez Arnold J, Salcedo S, Ketter TA, Calabrese JR, Rabideau DJ, Nierenberg AA, et al. An exploratory study of responses to low-dose lithium in African Americans and Hispanics. J Affect Disord 2015;178: 224-228.

12. Ghoneim MM, Korttila K, Chiang CK, Jacobs L, Schoenwald R, Mewaldt S, et al. Diazepam effects and kinetics in Caucasians and Orientals. Clin Pharmacol Ther 1981;29:749-756.

13. Kumana CR, Lauder IJ, Chan M, Ko W, Lin HJ. Differences in diazepam pharmacokinetics in Chinese and white Caucasians-relation to body lipid stores. Eur J Clin Pharmacol 1987;32:211-215.

14. Doyle JM. What race and ethnicity measure in pharmacologic research. J Clin Pharmacol 2006;46:401-404.

15. Chaudhry IB, Neelam K, Duddu V, Husain N. Ethnicity and psychopharmacology. J Psychopharmacol 2008;22:673-680.

16. Lin KM, Poland RE, Nuccio I, Matsuda K, Hathuc N, Su TP, et al. A longitudinal assessment of haloperidol doses and serum concentrations in Asian and Caucasian schizophrenic patients. Am J Psychiatry 1989; 146:1307-1311.

17. Ruiz P, Varner RV, Small DR, Johnson BA. Ethnic differences in the neuroleptic treatment of schizophrenia. Psychiatr Q 1999;70:163-172.

18. Frackiewicz EJ, Sramek JJ, Herrera JM, Kurtz NM, Cutler NR. Ethnicity and antipsychotic response. Ann Pharmacother 1997;31:1360-1369.

19. Miskimen T, Marin H, Escobar J. Psychopharmacological research ethics: special issues affecting US ethnic minorities. Psychopharmacology (Berl) 2003;171:98-104.

20. Daniel DG, Zimbroff DL, Potkin SG, Reeves KR, Harrigan EP, Lakshminarayanan M. Ziprasidone $80 \mathrm{mg} /$ day and $160 \mathrm{mg}$ /day in the acute exacerbation of schizophrenia and schizoaffective disorder: a 6-week 
placebo-controlled trial. Ziprasidone Study Group. Neuropsychopharmacology 1999;20:491-505.

21. Taylor D. Ziprasidone in the management of schizophrenia: the QT interval issue in context. CNS drugs 2003;17:423-430.

22. Prakash C, Kamel A, Gummerus J, Wilner K. Metabolism and excretion of a new antipsychotic drug, ziprasidone, in humans. Drug Metab Dispos 1997;25:863-872.

23. Mandrioli R, Protti M, Mercolini L. Evaluation of the pharmacokinetics, safety and clinical efficacy of ziprasidone for the treatment of schizophrenia and bipolar disorder. Expert Opin Drug Metab Toxicol 2015;11:149-174.

24. Lawson WB, Herman BK, Loebel A, Lazariciu I, Malik M. Ziprasidone in Black patients with schizophrenia: analysis of four short-term, double-blind studies. CNS Spectr 2009;14:478-486.

25. Stimmel GL, Gutierrez MA, Lee V. Ziprasidone: an atypical antipsychotic drug for the treatment of schizophrenia. Clin Ther 2002;24:21-37.

26. Kay SR, Fiszbein A, Opler LA. The positive and negative syndrome scale (PANSS) for schizophrenia. Schizophr Bull 1987;13:261-276.

27. Guy W. ECDEU Assessment Manual for Psychopharmacology. Rockville: US Department of Health, Education, and Welfare, Public Health Service, Alcohol, Drug Abuse, and Mental Health Administration, National Institute of Mental Health, Psychopharmacology Research Branch, Division of Extramural Research Programs; 1976.

28. Wilner K, Hansen R, Folger C, Geoffroy P. The pharmacokinetics of ziprasidone in healthy volunteers treated with cimetidine or antacid. Br J Clin Pharmacol 2000;49(Suppl):57S-60S.

29. Obach RS, Prakash C, Kamel AM. Reduction and methylation of ziprasidone by glutathione, aldehyde oxidase, and thiol s-methyltransferase in humans: an in vitro study. Xenobiotica 2012;42:1049-1057.

30. Beedham C, Miceli JJ, Obach RS. Ziprasidone metabolism, aldehyde oxidase, and clinical implications. J Clin Psychopharmacol 2003;23:229232.

31. Guengerich FP. Cytochrome P-450 3A4: regulation and role in drug metabolism. Annu Rev Pharmacol Toxicol 1999;39:1-17.

32. Gandelman K, Alderman JA, Glue P, Lombardo I, LaBadie RR, Versavel $\mathrm{M}$, et al. The impact of calories and fat content of meals on oral ziprasidone absorption: a randomized, open-label, crossover trial. J Clin Psychiatry 2009;70:58-62.

33. Conney AH, Pantuck EJ, Hsiao KC, Garland WA, Anderson KE, Alvares AP, et al. Enhanced phenacetin metabolism in human subjects fed charcoal-broiled beef. Clin Pharmacol Ther 1976;20:633-642.

34. Simoons FJ. Food in China: a Cultural and Historical Inquiry. Boca Raton: CRC Press; 1990.
35. Yang Y, Wang G, Pan X. The 2002 Chinese Food Composition Table: Beijing: Medical Publishing House of Beijing University; 2002.

36. Dugee O, Khor GL, Lye MS, Luvsannyam L, Janchiv O, Jamyan B, et al. Association of major dietary patterns with obesity risk among Mongolian men and women. Asia Pac J Clin Nutr 2009;18:433-440.

37. Juneja RK, Weitkamp LR, Stratil A, Gahne B, Guttormsen SA. Further studies of the plasma $\alpha 1 \mathrm{~B}$-glycoprotein polymorphism: two new alleles and allele frequencies in caucasians and in american blacks. Human Hered 1988;38:267-272.

38. Kremer JM, Wilting J, Janssen LH. Drug binding to human alpha-1-acid glycoprotein in health and disease. Pharmacol Rev 1988;40:1-47.

39. Fukuma Y, Kashimura S, Umetsu K, Yuasa I, Suzuki T. Genetic variation of alpha-2-HS-glycoprotein in the Kyushu district of Japan: description of three new rare variants. Hum Hered 1990;40:49-51.

40. Holthoewer D, Kirschbaum K, Frisch J, Hiemke C, Schmitt U. Pharmacodynamic effects of aripiprazole and ziprasidone with respect to p-glycoprotein substrate properties. Pharmacopsychiatry 2013;46:175-180.

41. Hodges LM, Markova SM, Chinn LW, Gow JM, Kroetz DL, Klein TE, et al. Very important pharmacogene summary: ABCB1 (MDR1, Pglycoprotein). Pharmacogenet Genomics 2011;21:152-161.

42. Prakash C, Kamel A, Cui D, Whalen R, Miceli J, Tweedie D. Identification of the major human liver cytochrome P450 isoform (s) responsible for the formation of the primary metabolites of ziprasidone and prediction of possible drug interactions. Br J Clin Pharmacol 2000;49 (Suppl 1):35S-42S.

43. Wilner K, Tensfeldt T, Baris B, Smolarek T, Turncliff R, Colburn W, et al. Single- and multiple-dose pharmacokinetics of ziprasidone in healthy young and elderly volunteers. Br J Clin Pharmacol 2000(Suppl 1);49:15S-20S

44. Keck PE Jr, Reeves KR, Harrigan EP; Ziprasidone Study Group. Ziprasidone in the short-term treatment of patients with schizoaffective disorder: results from two double-blind, placebo-controlled, multicenter studies. J Clin Psychopharmacol 2001;21:27-35.

45. Chue P, Mandel FS, Therrien F. The effect of ziprasidone on metabolic syndrome risk factors in subjects with schizophrenia: a 1 year, openlabel, prospective study. Curr Med Res Opin 2014;30:997-1005.

46. Miceli JJ, Tensfeldt TG, Shiovitz T, Anziano R, O'Gorman C, Harrigan RH. Effects of Oral Ziprasidone and Oral Haloperidol on QTc interval in patients with Schizophrenia or Schizoaffective disorder. Pharmacotherapy 2010;30:127-135.

47. Levy WO, Robichaux-Keene NR, Nunez C. No significant QTc interval changes with high-dose ziprasidone: a case series. J Psychiatr Pract 2004;10:227-232. 